\title{
Toolpath and machining parameters optimisation of the cavities of a knee prosthesis tibial insert
}

\author{
Francisco J. Lopes ${ }^{1, *}$, A. Completo ${ }^{2}$ (D) J. P. Davim² ${ }^{2}$ \\ ${ }^{1}$ Dept. of Mechanical Engineering and Industrial Management, Polytechnic Institute of Viseu, Campus \\ Politécnico, 3504-510 Viseu, Portugal \\ ${ }^{2}$ Dept. of Mechanical Engineering, University of Aveiro, Campus Universitário de Santiago, 3810-193 \\ Aveiro, Portugal \\ *Corresponding author. \\ E-mail address: fjlopes@ipv.pt
}

\section{Abstract}

The main purpose of this paper is to demonstrate the applicability of conventional cutting tools in the machining of a custom tibial insert of a knee prosthesis. This study also aims to reduce the roughness and minimize the production time. In this work the optimisation of cutting strategies and parameters was achieved through the design and construction of a test-part containing the most important complex surfaces of the femoral cavities, the focus of the study. The milling was carried out in accordance with the Design of Experiment and the Taguchi method and was performed in two stages to reduce the number of analysed factors. The achieved parameters are applied to the machining of a modelled tibial insert made of UHMWPE, using a NC machine with three axes. The initial parameters studied were the cutting method, axial and radial depth of cut, the direction of the feed and the feed rate. Three strategies were studied: two Blend, resulting in radial and spiral toolpaths, and one Parallel. According to the spiral strategy, an arithmetical mean roughness of $R_{a}=1.1 \mu \mathrm{m}$ was obtained, representing an improvement of $45 \%$ relatively to the initial phase value of $2.0 \mu \mathrm{m}$, with the Parallel toolpath. An 
overall improvement of $34 \%$ in time efficiency of the finishing operation was achieved after changing the machine settings. This study supports the conclusion that high-speed milling is an expeditious process to produce customized tibial inserts.

Key words: knee prosthesis tibial insert, high speed machining, UHMWPE, optimisation, milling toolpaths, cutting parameters.

\section{1 - Introduction}

Total knee arthroplasty (TKA) is an intervention, developed in the 1970s, consisting of replacing the joint between the femur and tibia and between the femur and patella ${ }^{1}$. In OECD countries, more than 1.6 million knee replacement surgeries are performed annually, and between 2000 and 2015 the rate of these surgeries increased almost $100 \%$ ${ }^{2}$. It is estimated that part of these surgeries, between $7 \%$ to $10 \%$, are revision procedures 3. The failure of the primary surgeries is due to factors such as, the durability of the prosthesis and the degree of precision verified in its placement. Furthermore, TKA is also performed on increasingly younger patients, which demands a more lasting result ${ }^{4}$. A recent review concluded that approximately $82 \%$ of total knee replacements have a lifetime of 25 years ${ }^{5}$, which is not enough for younger patients. The economic impact due to these factors can only be mitigated, achieving greater efficiency in primary surgeries, reducing the need for revision procedures and simultaneously increasing the durability of the prosthesis components. 
The time spent on surgery can be reduced with the use of customized cutting jigs, obtained with rapid prototyping techniques, and a better implant alignment is achieved with the spreading of new techniques, like computer-assisted TKA ${ }^{6}$. Together, these techniques increase implant survivorship and can also be associated with customized prostheses, allowing the use of dimensions or shapes that are more suitable to the patient's bone, without the constraints of using the available standard dimensions ${ }^{7}$. These approaches use data from preoperative imaging studies, such as magnetic resonance imaging or computerized tomography as a starting point ${ }^{8,9}$, generating the $3 \mathrm{D}$ design of the patient's bone. This model is used both in the preparation and virtualization of the surgery, as well as in the implant's customization. However, it is still necessary to convert the mass production process to the manufacture of customized prostheses. Even the recent application of the additive technology in the manufacture of customized UHMWPE tibial inserts by selective laser sintering ${ }^{10}$ requires additional machining operations in the femoral cavities to achieve the necessary surface quality. This paper shows and demonstrates the applicability of high speed machining in the unitary production of knee prosthesis components.

TKA prosthesis, shown in Fig. 1a, consists of a femoral component, a tibial tray, an interface between these two components, know as a tibial insert, and a patellar component, if needed.

The UHMWPE, due to its properties ${ }^{11-13}$, is the material used since the late 1960 s and is 
still today the "golden standard" polymer used in the manufacture of the patellar component and tibial insert ${ }^{14}$, whether in fixed or mobile bearing designs ${ }^{15,16}$.

There are many different designs of prostheses on the market ${ }^{17}$ and they essentially follow two main approaches that emerged in the 1970s and are still used today: anatomical and functional ${ }^{18}$. In the anatomical approach, the design allows the preservation of all or most of the soft tissues of the natural knee (anterior and posterior cruciate ligaments). In the functional designs, the non-anatomic surfaces are used to maximize the contact area, decreasing the stress forces in the polyethylene insert. Given the variety of existing configurations, this article focuses on the manufacturing process of a posterior-stabilized (PS) fixed bearing insert, that follows a functional approach, as can be seen in Fig. 1. This type of design incorporates a central post in the polyethylene component that fits into the femoral component, preventing displacement in the mediallateral direction and reducing the risk of femur-tibial dislocation. Fig. 1c and d show a CAD drawing of the insert made from a real model, pointing out the most important surfaces in contact with other components. This tibial insert is the prototype machined as an application of both strategy and cutting parameters optimization.

The femoral cavities, identified in Fig. 1d, allow the sliding movement of the femoral component, being subjected, in certain areas, to high stresses occurring at a reduced or near zero speed ${ }^{19}$. These conditions make the lubrication by synovial fluid more difficult and cause higher local wear. The femoral cavities are the most sensitive surfaces of the 
tibial insert and they have a complex geometry.

Problems with wear and fatigue damage of the UHMWPE have always limited the longevity of the knee prosthesis ${ }^{5,20}$. One of the main causes of failure is the aseptic loosening of implants due to an adverse reaction of the body, called osteolysis. Smaller particles generated from wear can stimulate an osteolytic response and the manufacturing process of the tibial insert can influence the clinical duration of the prosthesis ${ }^{12,21}$.

Many factors influence the wear mechanisms of UHMWPE tibial implants during in vivo friction, namely: machining process factors (metal counterface roughness, UHMWPE surface topography), implant design, surgical technique (knee alignment) and patient factors (body weight, synovial fluid properties) ${ }^{21,22}$. On the machining process factors, it has been shown that the polyethylene surface morphology, obtained by high speed machining, leads to a low friction coefficient in laboratory tests and less degradation of the surface ${ }^{23}$. However, there is limited information on the effect of machining parameters on UHMWPE tribological properties 13, 21, 23-26. This paper focuses on machining process variables, and, more precisely, on the main outcome factor, roughness.

Roughness can be predicted according to several approaches based on experimental investigation ${ }^{27-32}$, machining theory ${ }^{33}$, and numerical methods ${ }^{34,35}$. However, the latter is not yet widespread in CAM software. The strategies and cutting parameters are typically information protected by the manufacturers, and there is limited information available on the impact of these choices on roughness. The present study reports the 
impact of various machining scenarios on the surface finish of the femoral cavities of prosthesis. The approach followed in this article is based on experimental investigation.

\section{2 - Materials and Methods}

Different parameter combinations were studied using conventional cutting tools. The experiments were performed using a test-part and were planned according to the DOE method, based on Taguchi, in order to reduce the number of experiments performed. This

method is commonly used in the optimisation of machining parameters ${ }^{36-43}$. The experimental plan was developed in two stages. The final goal is to determine the best strategy and parameters to minimize the arithmetical mean roughness value $\left(R_{a}\right)$. In both stages, three levels of each factor are used, allowing probing non-linear behaviour. Main effects plots, response tables and variance analyses (ANOVA) statistical comparisons were used to evaluate the results. The outcome from the predicted optimised parameters was verified by an independent test.

\section{1 - First stage of testing}

In this first stage, the factors that most influence the surface quality of the toroidal cavities were identified. The cutting parameters controlled during the experiments were spindle speed $(n)$, feed rate $\left(f_{z}\right)$, effective cutting speeds, and axial $\left(a_{p}\right)$ and radial $\left(a_{e}\right)$ depth of cut. In addition to these variables, toolpath and machining strategies, which include the direction of the feed, were also tested. These parameters are defined in Fig. 2, 
emphasizing the differences between two methods of cutting, up-milling (the feed direction of the cutting tool is opposite to its rotation) and down-milling (the cutting tool is fed in the direction of rotation).

Four main factors were selected for each toolpath and, after analysis of the results, were ordered by their influence on the $R_{a}$ response variable. Through previous simulations in Mastercam X6, three toolpaths were selected to perform the finishing of the cavities: Parallel and two Blend variants, Fig. 2.

The Blend 1 strategy, the reference lines (chains), picked in the Mastercam as across, were the contour of the cavity divided into two, creating a trajectory similar to the radial one, but running through the cavity from one end to the other. In Blend 2 strategy, the contour and a point were indicated as along, resulting in a spiral or, optionally, an elliptical trajectory.

The three strategies generated three groups of distinct trials due to the specificity of the factors used in each one. Four factors were selected in each toolpath. The common parameters were the cutting method, $f_{z}$ and $a_{e}$, shown in Fig. 2. For the Parallel strategy, the fourth factor was the orientation of the toolpath, with zero degrees corresponding to the direction along the minor axis of the elliptical contour, 90 degrees along the major axis and, finally, 45 degrees relative to the previous axes, Fig. 2. In the Blend 1 toolpath (radial type), the axial depth of cut was added which is coincident with the value of the over-thickness left by the semi-finishing operation. For the Blend 2 strategy, the location 
of the reference point also varied: in the centre of the cavity $\left(\mathrm{P}_{0}\right)$, in position $1\left(\mathrm{P}_{1}\right.$; $\left.\mathrm{X}_{1}=0 \mathrm{~mm}, \mathrm{Y}_{1}=6 \mathrm{~mm}\right)$ and position $2\left(\mathrm{P}_{2} ; \mathrm{X}_{2}=-4 \mathrm{~mm}, \mathrm{Y}_{2}=6 \mathrm{~mm}\right)$, Fig. 2 . The factors and their respective levels are summarized in Table 1. In the toolpaths tested, the maximum distance between passages was $0.12 \mathrm{~mm}$. In accordance with the theoretical equations of crest height and arithmetic mean deviation of the profile defined by Quintana ${ }^{33}$, a profile height of $H=0.60 \mu \mathrm{m}$ and $R_{a}$ theoretic $=0.30 \mu \mathrm{m}$, were determined, considering a $\varnothing=6 \mathrm{~mm}$ ball end mill and $a_{e}=0.12 \mathrm{~mm}$ in a flat plane. However, the femoral surface is not flat. Furthermore, the cutting of material is an intermittent action, i.e. in the feed direction, the roughness is also affected by the selected value of the feed rate. For flat surfaces where $f_{Z}=0.096 \mathrm{~mm} /$ tooth, the maximum crest of height will be $H=0.38 \mu \mathrm{m}^{33}$. For the Parallel strategy, the down-milling and up-milling levels characterize the cutting method in the first half of the cavity, because in the second half, the material appears on the opposite side. The experiment plan was drawn up using orthogonal array $\mathrm{L}_{9}\left(3^{4}\right)$ - four factors with three levels each.

\section{2 - Second stage of tests}

In the second test stage, the two most relevant factors resulting from the ordering of stage 1 were selected for further analysis; for the remaining factors, the optimal level determined in stage one was used. The factors continued with three levels. The maximum resolution of the $\mathrm{L}_{9}\left(3^{2}\right)$ array (factorial) was used to define the experiments. The reduced matrices of Taguchi used in the first stage of tests, the complete factorial arrangements of 
the second phase, and the statistical treatment of the results were performed through Minitab 17 software.

\section{3 - Confirmation experiments}

The last step in the Taguchi method is to carry out new tests that confirm the results from the optimal levels of each factor, obtained in previous experiments. In addition, the most important factor was tested in six levels, keeping the remaining factors at their optimal level, in order to make the adjustment line more significant. Thus, the regression equation was adjusted considering six values: the three points from the levels tested in the second stage, the two intermediate points and a last point outside the previously tested domain. The selected side of this last point was the one that optimised the $R_{a}$ parameter. The points considered are all equidistant and each experiment was replicated twice.

\section{4 - Test-part definition}

In the design of a test-part, the main geometric forms of the prosthesis are summarized and reproduced. This concept, commonly used in the optimisation of machining parameters, facilitates the execution of the experiments and allows a direct comparison of the results ${ }^{41,44-47}$. After the optimisation of the parameters in the test-part, these are applied in the manufacture of the final component. The need to use nine tests for each toolpath led to the design of a test-part with nine cavities in a polyethylene block with approximate dimensions of 177x 103x20 [mm]. Based on the analysis of real tibial inserts, 
the femoral cavities were simplified and parameterized as part of the surface of a doughnut, Fig. 3. The radius of revolution of the cross-section measures $37 \mathrm{~mm}$. The transverse circular section has a radius of $23 \mathrm{~mm}$, resulting in a cavity with a $60 \mathrm{~mm}$ longitudinal outer radius. The cavity has a maximum depth (at the central point) equal to $5 \mathrm{~mm}$, a maximum width of $48 \mathrm{~mm}$ and a minimum of $29 \mathrm{~mm}$, approximately. The testpart also incorporates other geometric elements, such as contours with various radii of curvature, spherical slices and slots. A test-part in each replication was machined and each experiment was replicated twice.

\section{5 - Simulation and machining}

The trajectories were generated and simulated using Mastercam X6 software and the postprocessed programs were introduced in the CNC machine with tree axes, Fig. 3. In the first stage of tests, the axis of rotation of the end mill was perpendicular to the upper surface of the initial stock, $\alpha=0^{\circ}$ illustrated in Fig. 3. In the remaining tests, the initial stock was tilted 45 degrees relative to the same axis $\left(\alpha=45^{\circ}\right)$. The roughing of the cavities was performed with the same strategy, parameters and cutting tool. The semi-finishing operation was performed with the same cutter, using the area clearance strategy, producing a spiral toolpath and leaving a uniform over thickness equal to the axial depth of cut with the Blend 1 trajectory and $0.3 \mathrm{~mm}$ in the other cases. In the finishing operations a $6 \mathrm{~mm}$ ball solid carbide end mill was used, with two teeth and a 
flute helix angle of 50 degrees, and a spindle speed of $n=9500 \mathrm{rpm}$. The cooling of the workpiece and tool was performed with compressed air, directed at the cutting interface.

\section{6 - Evaluation of the surface quality of the cavity}

The experimental assembly used to obtain the surface roughness readings in the cavities consists of a manual column stand with a platform that supports the test-part, on a levelling table, where the drive unit was supported, and on a display unit control that stores data. The surface finish was measured in 15 zones per cavity. In each zone, two readings were taken along perpendicular directions. Thus, each cavity was evaluated by the average of 30 readings with positions as shown in Fig. 3. The $R_{a}$ value that characterizes each experiment was calculated by the mean of the two replicates of the cavity. The contact roughness tester had a standard stylus, with $0.75 \mathrm{mN}$ of measuring force and $2 \mu \mathrm{m}$ tip radius. The reading conditions considered a $R$ profile with digital Gaussian filter, $800 \mu \mathrm{m}$ of measuring range $(0.01 \mu \mathrm{m}$ resolution $), 0.5 \mathrm{~mm} / \mathrm{s}$ of reading speed, $0.8 \mathrm{~mm}$ of cut-off length, and a total evaluation length of $4.0 \mathrm{~mm}$ (number of sampling lengths $=5$ ), making the total travel length of the detector $4.8 \mathrm{~mm}$.

\section{3 - Results and Discussion}

\section{1 - First stage of testing}

The combination of the levels and the results obtained for each test, as well as their mean, are shown in Table 2. The optimal levels of each factor and the response tables for the $R_{a}$ 
parameter of the three toolpath tested were determined based on these results. The optimal levels were A2-B1-C3-D2, with the Parallel toolpath, A3-B1-C3-D2, with Blend 1 strategy and A1-B1-C1-D2, with the Blend 2, minimizing the value of the $R_{a}$ parameter. In all trajectories, the optimum level for the feed rate was the intermediate level of $f_{z}=0.093 \mathrm{~mm} /$ tooth, and for the $a_{e}$ was the lowest value of $0.08 \mathrm{~mm}$. The lower mean $R_{a}=1.19 \mu \mathrm{m}$ was obtained in sample 7 of the Blend 1 strategy, where all the optimal levels of each factor were used. This strategy also presented the smaller variation in the nine cavities, essentially due to the lower results observed in the centre of the surface, where the cutter passed several times. Analysing the value of $R_{a}$ by zone, the centre of the cavity had poor finishing on all the toolpaths, especially on the Parallel with $R_{a}=3.38 \mu \mathrm{m}$ (the mean of all experiments in the middle region: cells $\mathrm{C} 2$, D2 and centre, Fig. 3). The central zone, visibly affected by this effect, has a length of approximately 18 $\mathrm{mm}$, which means that the central part of the ball end mill, with a radius of less than 0.45 $\mathrm{mm}$, produces a very low effective cutting speed, whose minimum value is zero at the central point. To prevent contact between the milling cutter and the cavity surface from distances of less than $0.45 \mathrm{~mm}$, the test-part must be tilted at least $\alpha=32.2^{\circ}$, so that the cutter does not machine in a level below the affected area. With the Blend 2 toolpath, changing the location of the middle point did not avoid a worse finishing of the central zone. The centred trajectory minimizes the operating time by shortening the total distance travelled by the tool, used in the following experiments. 
With Parallel toolpath, the up-milling or down-milling method produced very similar results. This is justified due to the switching of the cutting method from up-milling in the first half of the cavity to down-milling in the second half and vice versa. As expected, the overall result of these two levels is identical and achieves a better finish compared to that in which the material is removed in both forward and backward paths (zig-zag level). The best orientation for this toolpath was zero degrees, along the minor axes of the cavity contour.

The response tables allowed the ranking of each factor on the $R_{a}$ parameter for the three toolpaths, in Table 3. In the two most important parameters, the cutting method was included in all toolpaths. The $a_{e}$ was the first and second most important factor for the Parallel and Blend 2 respectively, while for Blend 1, the most significant parameter was the feed rate. With Blend 1 , the $a_{p}$ and $a_{e}$ caused small variations in roughness. The Blend 2 toolpath is the one with the greatest variation between levels, with a greater capacity to be optimized in the second testing stage.

\section{2 - Second stage of testing}

The levels were adjusted seeking to obtain lower values of roughness. The optimum level of the previous tests was selected as the intermediate level of this stage. The extreme values have been adjusted so that their mean was the new intermediate level and differences between levels were also increased. The factors and their new levels are presented in Table 4. The machining tests of this stage used the new slope of the cavities 
$\left(\alpha=45^{\circ}\right)$ in the three strategies. According to this change, the Parallel strategy now has three full levels in the cutting method, allowing the same cutting method across the surface.

The new combination of the levels and the results of $R_{a}$ in each test are provided in Table 5. Their analysis shows that sample 3 of the Blend 2 strategy reached the lowest mean, $R_{a}$ $=1.20 \mu \mathrm{m}$, using the smallest increment $\left(a_{e}=0.050 \mathrm{~mm}\right)$ and the elliptical cut method. The worst value, $R_{a}=1.83 \mu \mathrm{m}$, was obtained for sample 9 of the Parallel trajectory, which applied the higher increment $\left(a_{e}=0.050 \mathrm{~mm}\right)$ and the double-direction cut method. This last trajectory has, on average, $R_{a}=1.67 \mu \mathrm{m}$, the worst result. The wider range in results continued to belong to the Blend 2 strategy, showing a higher sensitivity to the tested factors.

The $R_{a}$ values measured in the central zone of the cavity are lower than those measured in the first stage and more uniform relative to the other regions. This is justified by the absence of abrasion of the surface through the central part of the milling cutter. This improvement ensures that there is always a real cut across the cavity. The mean value of all the cavities in the central zone is $1.62 \mu \mathrm{m}$ with the Parallel toolpath, $0.98 \mu \mathrm{m}$ for the Blend 1 and $1.21 \mu \mathrm{m}$ for the Blend 2 strategy, showing that tilting the workpiece 45 degrees avoids the abrasion issue. The Blend 1 toolpath continues to benefit from the multiple passages in the central zone; however, the differences are now much smaller, compared to the other two trajectories. 
With the Blend strategies, there are some zones with mean values of $R_{a}$ lower than $1 \mu \mathrm{m}$, whose lowest value is $0.8 \mu \mathrm{m}$ with Blend 2. The main effect graph in Fig. 4 presents the optimal levels of each factor for the three toolpaths: E1-F1, for the Parallel strategy, E3F3, for the Blend 1 strategy and E1-F1, for the Blend 2 strategy. The optimum level of $a_{e}$ was registered for the lowest value $0.05 \mathrm{~mm}$ (Parallel and Blend 2). With the best trajectory, Blend 2, the most suitable cutting method was the spiral counter clockwise direction, but the differences between the three levels are very small, less than $0.042 \mu \mathrm{m}$, shown in Table 6. On the opposite side, the factor with the most impact (delta= $0.275 \mu \mathrm{m})$ is the $a_{e}$, with practically linear behaviour, Fig. 4 .

The response tables show that the $a_{e}$ is the dominant factor in the Parallel and Blend 2 toolpaths, and the cutting method in the remaining trajectory. Table 7 summarizes the ANOVA results, presenting each factor's contribution to the $R_{a}$ value, its significance level and its regression equation. With a 95\% confidence interval (CI) and 5\% significance level, in the Parallel toolpath, both factors are statistically significant justifying $59.3 \%\left(a_{e}\right)$ and $33.1 \%$ (cutting method) of the results, with the remaining $7.6 \%$ being allocated to error. With Blend 1 the $f_{z}$ is statistically not significant, leaving the $R_{a}$ constant in each level of the cutting method, the best being $1.28 \mu \mathrm{m}$ at the zig-zag level. The last factor accounts for $68.2 \%$ of the results. The $a_{e}$ factor, in the Blend 2 strategy, justifies almost the entire $R_{a}$ variation ( $94.8 \%$ of variance explained), with the cutting method and their interaction not being statistically significant. Therefore, the error and 
other uncontrolled factors were smaller in this strategy, accounting for only $5.2 \%$. Analysing the regression equations in Table 7, we conclude that the spiral toolpath is the one with the lowest $R_{a}$ value for the same $a_{e}$, which at the limit leads to $R_{a}=1.0 \mu \mathrm{m}$. This conclusion was confirmed by new experiments whose results are shown below.

\section{3 - Confirmation tests}

Table 8 shows the results of the confirmation tests for the best toolpath of the second stage, with the $a_{e}$ factor varying in six levels and keeping the spiral ccwise level. Sample $1\left(\boldsymbol{a}_{e}=\right.$ $0.035 \mathbf{m m}$ ) of the Blend 2 strategy presented a minimum value of $\boldsymbol{R}_{a}=\mathbf{1 . 1 3} \boldsymbol{\mu m}$, confirming the trend of the optimal level. Fig. 5a presents the linear regression and the lines relating to the $95 \%$ confidence and prediction intervals, showing that all the tests are comprised within these ranges. The prediction equation of the second stage practically matches with the trend line of the confirmation tests, with a maximum difference of $2.4 \%$ $(0.036 \mu \mathrm{m})$ for $a_{e}=0.11 \mathrm{~mm}$ within the domain, Fig. $5 \mathrm{~b}$. For the optimum level of the second stage ( $a_{e}=0.050 \mathrm{~mm}$ ), the $R_{a}$ value was $1.30 \mu \mathrm{m}$, differing from the prediction by $+5.4 \%$, Fig. $5 \mathrm{~b}$. This level of the confirmation tests, through linear regression, has a $+0.3 \%$ difference when compared to the previous prediction.

The mean result, by zone, for $a_{e}=0.035 \mathrm{~mm}$ is shown in Fig. 5c. The results of the second stage were confirmed with respect to the central zone of the cavity, obtaining $R_{a}=1.1$ $\mu \mathrm{m}$. In the confirmation test, as in the previous ones, some areas with $R_{a}$ values lower than $1 \mu \mathrm{m}$ were found, whose lowest value is $0.82 \mu \mathrm{m}$. The machining results of the right 
side of the cavity obtained a $20 \%$ better finish than the left side. This fact can be justified by the upward trajectory of the right half with the central strip having an intermediate value ( $6.5 \%$ better), as it contains both directions. In the lower half, it was also found that the $R_{a}$ results are $13 \%$ better than on the upper half. In this case, the difference can be justified by the effective cutting speed, which is lower at the bottom, producing a smoother surface finish.

The ANOVA of the linear regression, presented in Table 9, confirmed that $a_{e}$ is statistically significant, explaining about $85.6 \%$ of the results. This score is $9 \%$ lower than those of the second stage, but it accounts for a wider range. The standard error, $S=0.050 \mu \mathrm{m}$, is an acceptable value.

Fig. 5d and e illustrates the time of the confirmation tests related to the $R_{a}$ and $a_{e}$ variables, respectively. Reducing the $R_{a}$ from $1.30 \mu \mathrm{m}$ to $1.13 \mu \mathrm{m}$ requires twice the production time. There is a mismatch between the time provided by the Mastercam, marked with the green line on the graph, and the measured time (the red line). This difference is justified by the high number of points that builds the trajectory, and it is not possible to reach the programmed feed rate in the entire cavity. This phenomenon is most pronounced closer to the centre of the cavity. The time consumed can be significantly reduced if the protection of the $\mathrm{CNC}$ machine is deactivated against sudden acceleration/deceleration. With this change, a $34 \%$ reduction in the duration of the operation was achieved, when $a_{e}=0.035 \mathrm{~mm}$. The impact in the remaining cases was smaller, at only $12 \%$ when 
$a_{e}=0.110 \mathrm{~mm}$. This change was applied only during this toolpath, since during its execution there are no large or quick movements in the safety plane, making the existing movements more continuous and smoother.

The optimum set of control factors for the most effective toolpath, Blend 2, is: feed in spiral counter clockwise, reference point centred, $a_{e}=0.035 \mathrm{~mm}$, $f_{z}=0.093 \mathrm{~mm} /$ tooth, with an outcome of $R_{a}=1.13 \mu \mathrm{m}$ and time at 54 minutes.

\section{4 - Application - tibial insert}

The toolpath and optimised parameters were applied in the execution of a tibial insert. In the manufacturing process, the fourth axis of the $\mathrm{CNC}$ was used. The rotation of this axis, allowed the machining of several planes with the same fixture. In the first phase of the process, the most important surfaces of the insert were machined (whose dimensional accuracy must be greater), including the two femoral cavities (to the left in Fig. 6). After the first phase, the workpiece was still attached laterally to the initial rod. After the removal of the tops, lateral contouring operations were performed, in a second fixture and using only three-axis machining in order to remove excess material, as shown in the centre of Fig. 6. The resulting part of the entire manufacturing process is illustrated, in several directions, on the right, in Fig. 6. In the femoral cavities a mean of $R_{a}=1.16 \mu \mathrm{m}$ was achieved, similar to the values of the confirmation tests. 


\section{4 - Conclusions}

This work aimed to optimise high speed machining parameters to obtain the best possible surface finish of the femoral cavities of the tibial insert using a conventional ball end mill and a three-axes CNC machine. Several milling experiments of a UHMWPE test piece were implemented with the Taguchi method designed in two stages, with L9 arrays, and statistical analyses, like ANOVA. The optimal set of parameters and a prediction equation were validated by the confirmation milling experiments. The main conclusions of this work are as follows:

i) ANOVA results determined the most important parameter on $R_{a}$ to be the stepover, at $59.3 \%$ and $94.8 \%$, with Parallel and Blend 2 toolpaths respectively, and the cutting method, at $68.2 \%$, with Blend 1 strategy.

ii) The Blend 2 strategy, leading to a continuous spiral toolpath, decreased the mean value of $R_{a}$ for the cavities.

iii) The optimal $R_{a}$ values for the cutting method, feed rate, radial depth of cut, and chains were determined: feed in counter clockwise, $0.093 \mathrm{~mm} /$ tooth $(1767 \mathrm{~mm} / \mathrm{min}), 0.035 \mathrm{~mm}$, and with the centre point and the elliptical contour of the cavity given as along and $3 \mathrm{D}$, respectively.

iv) The limitation of the 3 axes machining, to prevent abrasion in the central part of the cutter, can be overcome by tilting the workpiece 45 degrees relative to 
the tool axis, improving local values of $R_{a}$ from $3.4 \mu \mathrm{m}$ to $1.1 \mu \mathrm{m}$. All toolpaths benefited from this change.

v) Under these conditions, the best mean $R_{a}$ value, controlled in 15 zones and for two perpendicular directions, was $1.13 \mu \mathrm{m}$. The time spent in this finishing operation was 54 minutes. The $R_{a}$ values can be predicted by the expression $R_{a}[\mu \mathrm{m}]=1.04+3.93 * a_{e}[\mathrm{~mm}]$, with a standard error of $0.05 \mu \mathrm{m}$ and $a_{e} \in$ $[0.035,0.110 \mathrm{~mm}]$, and

vi) The obtained $R_{a}$ values differ greatly from the theoretical values for flat surfaces machined by a ball end mill. For example, according to the theoretical equations for $a_{e}=0.12 \mathrm{~mm}, R_{a}$ is $0.6 \mu \mathrm{m}$ and, experimentally, the value obtained was $R_{a}=2.0 \mu \mathrm{m}$, with Parallel toolpath.

vii) The parameter statistically relevant in the linear regression is the radial depth of cut, with a contribution of approximately $86 \%$, and the remaining percentage attributed to uncontrolled factors.

viii) Using the obtained correlation, for lower radial depth of cut values and the limit equal to zero, a $R_{a}$ value close to $1.0 \mu \mathrm{m}$ would be obtainable. However, this parameter selection would have a negative impact on runtime.

ix) The production time was predicted by quadratic equations, as a function of the $R_{a}$ and as function of $a_{e}$. Lowering the $R_{a}$ from $1.30 \mu \mathrm{m}$ to $1.13 \mu \mathrm{m}$ increments 
the time by $93 \%$. Decreasing the $a_{e}$ from 0.05 to $0.035 \mathrm{~mm}$ raises the time by $70 \%$.

x) The spiral toolpath allows deactivating the protection of the CNC machine against sudden acceleration/deceleration, saving 12 to $34 \%$ of the finishing time, respectively for the highest $\left(a_{e}=0.110 \mathrm{~mm}\right)$ and the lowest $\left(a_{e}=0.035\right.$ mm) tested $a_{e}$ value.

xi) According to the confirmation test, the $R_{a}$ measurements are within the $95 \%$ confidence and prediction intervals.

The full execution of the tibial insert prototype, using strategy and the optimum set of cutting parameters and carried out with conventional tools, took approximately 2 hours and 20 minutes, achieving similar values of roughness $\left(R_{a}=1.16 \mu \mathrm{m}\right)$ in the femoral cavities, compared to those obtained in the test piece. This study shows that with conventional tools and three axes CNC machining it is possible to produce an UHMWPE tibial insert with a good roughness quality and with a thin thickness of $6 \mathrm{~mm}$ in the middle section of the femoral cavities.

Acknowledgments:

The authors acknowledge Project No. 031556-FCT/02/SAICT/2017; FAMASISustainable and intelligent manufacturing by machining, financed by the Foundation for Science and Technology (FCT), POCI, Portugal, in the scope of TEMA, Centre for Mechanical Technology and Automation - UID/EMS/00481/2013. 


\section{References}

1. Kurtz SM. Chapter 2 - From Ethylene Gas to UHMWPE Component: The Process of Producing Orthopedic Implants. In: Kurtz SM, (ed.). UHMWPE Biomaterials Handbook (Third Edition). Oxford: William Andrew Publishing, 2016, p. 7-20.

2. OECD. "Hip and knee replacement". Health at a Glance 2017: OECD Indicators. Paris: OECD Publishing 2017, p. 178 - 9

3. Watters TS, Mather RC, 3rd, Browne JA, Berend KR, Lombardi AV, Jr. and Bolognesi MP. Analysis of procedure-related costs and proposed benefits of using patient-specific approach in total knee arthroplasty. Journal of surgical orthopaedic advances. 2011; 20: 112-6.

4. Macdonell JR and Browne JA. Procedure 40 - Methods of Fixation in Total Knee Arthroplasty. In: Miller MD, Browne JA, Cole BJ, Cosgarea AJ and Owens BD, (eds.). Operative Techniques: Knee Surgery (Second Edition). Elsevier, 2018, p. 366-9.

5. Evans JT, Walker RW, Evans JP, Blom AW, Sayers A and Whitehouse MR. How long does a knee replacement last? A systematic review and meta-analysis of case series and national registry reports with more than 15 years of follow-up. The Lancet. 2019; 393: 655-63.

6. Panjwani TR, Mullaji A, Doshi K and Thakur H. Comparison of Functional Outcomes of ComputerAssisted vs Conventional Total Knee Arthroplasty: A Systematic Review and Meta-Analysis of HighQuality, Prospective Studies. The Journal of Arthroplasty. 2019; 34: 586-93.

7. Schroeder L and Martin G. In Vivo Tibial Fit and Rotational Analysis of a Customized, Patient-Specific TKA versus Off-the-Shelf TKA. J Knee Surg. 2019; 32: 499-505.

8. Wu X-D, Xiang B-Y, Schotanus MGM, Liu Z-H, Chen Y and Huang W. CT- versus MRI-based patientspecific instrumentation for total knee arthroplasty: A systematic review and meta-analysis. The Surgeon. 2017; 15: 336-48.

9. Dirks A, Bergmann M, Mai S, Müller D and Siebert W. A prospective multicentric analysis of patient data and functional tests of standard knee prosthesis compared to individualized knee prosthesis implantation (NexGen CR vs. ConforMIS iTotal CR). Orthopaedic Journal of Sports Medicine. 2018; 6: 2325967118 S00033.

10. Changhui S, Aibing H, Yongqiang $\mathrm{Y}, \mathrm{Di}$ W and Jia-kuo Y. Customized UHMWPE tibial insert directly fabricated by selective laser sintering. The International Journal of Advanced Manufacturing Technology. 2016; 85: 1217-26.

11. Malito LG, Arevalo S, Kozak A, Spiegelberg S, Bellare A and Pruitt L. Material properties of ultra-high molecular weight polyethylene: Comparison of tension, compression, nanomechanics and microstructure across clinical formulations. Journal of the Mechanical Behavior of Biomedical Materials. 2018; 83: 9-19. 
12. Zaribaf F. Medical-grade Ultra-high Molecular Weight Polyethylene: Past, Current, and Future. 2018.

13. Aldwell B, Hanley R and O'Donnell GE. Characterising the machining of biomedical grade polymers. Proceedings of the Institution of Mechanical Engineers, Part B: Journal of Engineering Manufacture. 2014; 228: 1237-51.

14. Chakrabarty G, Vashishtha M and Leeder D. Polyethylene in knee arthroplasty: A review. Journal of clinical orthopaedics and trauma. 2015; 6: 108-12.

15. Ollivier M, Parratte S, Flecher $X$ and Argenson J-N. The Mobile-bearing TKA: Is There Still a Place? Techniques in Orthopaedics. 2018; 33: 25-8.

16. Van Hamersveld KT, Marang-Van De Mheen PJ, Van Der Heide HJL, Van Der Linden-Van Der Zwaag HMJ, Valstar ER and Nelissen RGHH. Migration and clinical outcome of mobile-bearing versus fixedbearing single-radius total knee arthroplasty. Acta Orthop. 2018; 89: 190-6.

17. Nowakowski AM, Vavken P, Pagenstert $G$ and Valderrabano V. Chapter 8 - Design, Shape, and Materials of Total Knee Replacement. In: Hirschmann MT and Becker R, (eds.). The Unhappy Total Knee Replacement: A Comprehensive Review and Management Guide. Cham: Springer International Publishing, 2015, p. 85-97.

18. Causero A, Di Benedetto P, Beltrame A, Gisonni R, Cainero V and Pagano M. Design evolution in total knee replacement: which is the future? Acta bio-medica : Atenei Parmensis. 2014; 85 Suppl 2: 5-19.

19. Garabédian C, Bigerelle M, Najjar D and Migaud H. Wear pattern on a retrieved Total Knee Replacement: The "fourth body abrasion". Biotribology. 2017; 11: 29-43.

20. Sharkey PF, Lichstein PM, Shen C, Tokarski AT and Parvizi J. Why Are Total Knee Arthroplasties Failing Today-Has Anything Changed After 10 Years? The Journal of Arthroplasty. 2014; 29: 1774-8.

21. Sava MM, Munteanu B, Renault E, Berthier $Y$ and Trunfio-Sfarghiu AM. Tribological Analysis of UHMWPE Tibial Implants in Unicompartmental Knee Replacements: From Retrieved to In Vitro Studies. Biotribology. 2018; 13: 1-15.

22. Varadarajan KM, Oral E, Muratoglu OK and Freiberg AA. Why All Tibial Polyethylene Bearings are Not the Same? Techniques in Orthopaedics. 2018; 33: 17-24.

23. Popa M, Wang N, Descartes S and Sfarghiu a-m. Role of Surface Industrial Finishing Process of Joint Implant UHMWPE on their Tribological Behaviour. 2014, p.465-70.

24. Menezes PL and Kailas SV. Role of surface texture and roughness parameters on friction and transfer film formation when UHMWPE sliding against steel. Biosurface and Biotribology. 2016; 2: 1-10.

25. Wang FC, Jin ZM, McEwen HMJ and Fisher J. Microscopic asperity contact and deformation of ultrahigh molecular weight polyethylene bearing surfaces. Proceedings of the Institution of Mechanical Engineers, Part H: Journal of Engineering in Medicine. 2003; 217: 477-90. 
26. Guenther LE, Turgeon TR, Bohm ER and Brandt J-M. The biochemical characteristics of wear testing lubricants affect polyethylene wear in orthopaedic pin-on-disc testing. Proceedings of the Institution of Mechanical Engineers, Part H: Journal of Engineering in Medicine. 2015; 229: 77-90.

27. Shintoku K and Narita H. Study on Ball End Milling of Inclined Surfaces for Ultra High Molecular Weight Polyethylene. International Journal of Automation Technology. 2017; 11: 948-57.

28. Dikshit MK, Puri AB and Maity A. Analysis of cutting force coefficients in high-speed ball end milling at varying rotational speeds. Machining Science and Technology. 2017; 21: 416-35.

29. Kara F and Öztürk B. Comparison and optimization of PVD and CVD method on surface roughness and flank wear in hard-machining of DIN 1.2738 mold steel. Sensor Review. 2018.

30. Zhang L, Huang Y, Chen G, Xu M, Xia W and Fu Y. Experimental study of coverage constraint abrasive flow machining of titanium alloy artificial joint surface. Proceedings of the Institution of Mechanical Engineers, Part B: Journal of Engineering Manufacture. 2019; 233: 2399-409.

31. Paschoalinoto NW, Bordinassi EC, Bortolussi R, Leonardi F and Delijaicov S. The effect of process parameters and cutting tool shape on residual stress of SAE 52100 hard turned steel by high speed machining. Proceedings of the Institution of Mechanical Engineers, Part B: Journal of Engineering Manufacture. 2020: 0954405420929788.

32. Zhao G, Su Y, Zheng G, Zhao Y and Li C. Tool tip cutting specific energy prediction model and the influence of machining parameters and tool wear in milling. Proceedings of the Institution of Mechanical Engineers, Part B: Journal of Engineering Manufacture. 2020: 0954405420911298.

33. Quintana G, Ciurana Jd and Ribatallada J. Surface Roughness Generation and Material Removal Rate in Ball End Milling Operations. Materials and Manufacturing Processes. 2010; 25: 386-98.

34. Xu J, Zhang H and Sun Y. Swept surface-based approach to simulating surface topography in ball-end CNC milling. The International Journal of Advanced Manufacturing Technology. 2018; 98: 107-18.

35. Álvarez Á, Calleja A, Arizmendi M, González H and Lopez de Lacalle LN. Spiral Bevel Gears Face Roughness Prediction Produced by CNC End Milling Centers. Materials (Basel, Switzerland). 2018; 11: 1301.

36. Saptaji K, Gebremariam MA and Azhari MABM. Machining of biocompatible materials: a review. The International Journal of Advanced Manufacturing Technology. 2018; 97: 2255-92.

37. Hazir E, Erdinler ES and Koc KH. Optimization of CNC cutting parameters using design of experiment (DOE) and desirability function. Journal of Forestry Research. 2018; 29: 1423-34.

38. Nghiep TN, Sarhan AAD and Aoyama H. Analysis of tool deflection errors in precision CNC end milling of aerospace Aluminum 6061-T6 alloy. Measurement. 2018; 125: 476-95.

39. Mersni W, Boujelbene M, Salem SB and Alghamdi AS. Optimization of the surface roughness in ball end milling of titanium alloy Ti-6Al-4V using the Taguchi Method. Procedia Manufacturing. 2018; 20: 271-6. 
40. Lauro CH, Pereira RBD, Brandão LC and Davim JP. Design of Experiments - Statistical and Artificial Intelligence Analysis for the Improvement of Machining Processes: A Review. In: Davim JP, (ed.). Design of Experiments in Production Engineering. Cham: Springer International Publishing, 2016, p. 89-107.

41. Kara F. Taguchi optimization of surface roughness and flank wear during the turning of DIN 1.2344 tool steel. Materials Testing. 2017; 59: 903-8.

42. Öztürk B and Kara F. Calculation and Estimation of Surface Roughness and Energy Consumption in Milling of 6061 Alloy. Advances in Materials Science and Engineering. 2020; 2020: 1-12.

43. Chang H-J, Chen S-L and Lee P-Y. Using the direct cutting paths approach on aluminum alloy cone frustum part for evaluating a five-axis machine tool with Taguchi method. Proceedings of the Institution of Mechanical Engineers, Part B: Journal of Engineering Manufacture. 2017; 231: 881-8.

44. Ma J-w, Jia Z-y, Wang F-j and Ning F-d. Spindle Speed Selection for High-Speed Milling of Titanium Alloy Curved Surface. Materials and Manufacturing Processes. 2014; 29: 364-9.

45. Volpato $\mathrm{N}$ and de Amorim JR. A procedure for dealing with milling limitations in machined prototype tooling. Proc Inst Mech Eng Part B-J Eng Manuf. 2011; 225: 2163-76.

46. Wang W, Jiang Z, Tao W and Zhuang W. A new test part to identify performance of five-axis machine tool-part I: geometrical and kinematic characteristics of $\mathrm{S}$ part. The International Journal of Advanced Manufacturing Technology. 2015; 79: 729-38.

47. Wang L, Li W, Si H, Yuan X and Liu Y. Geometric deviation reduction method for interpolated toolpath in five-axis flank milling of the S-shaped test piece. Proceedings of the Institution of Mechanical Engineers, Part B: Journal of Engineering Manufacture. 2019; 234: 910-9. 


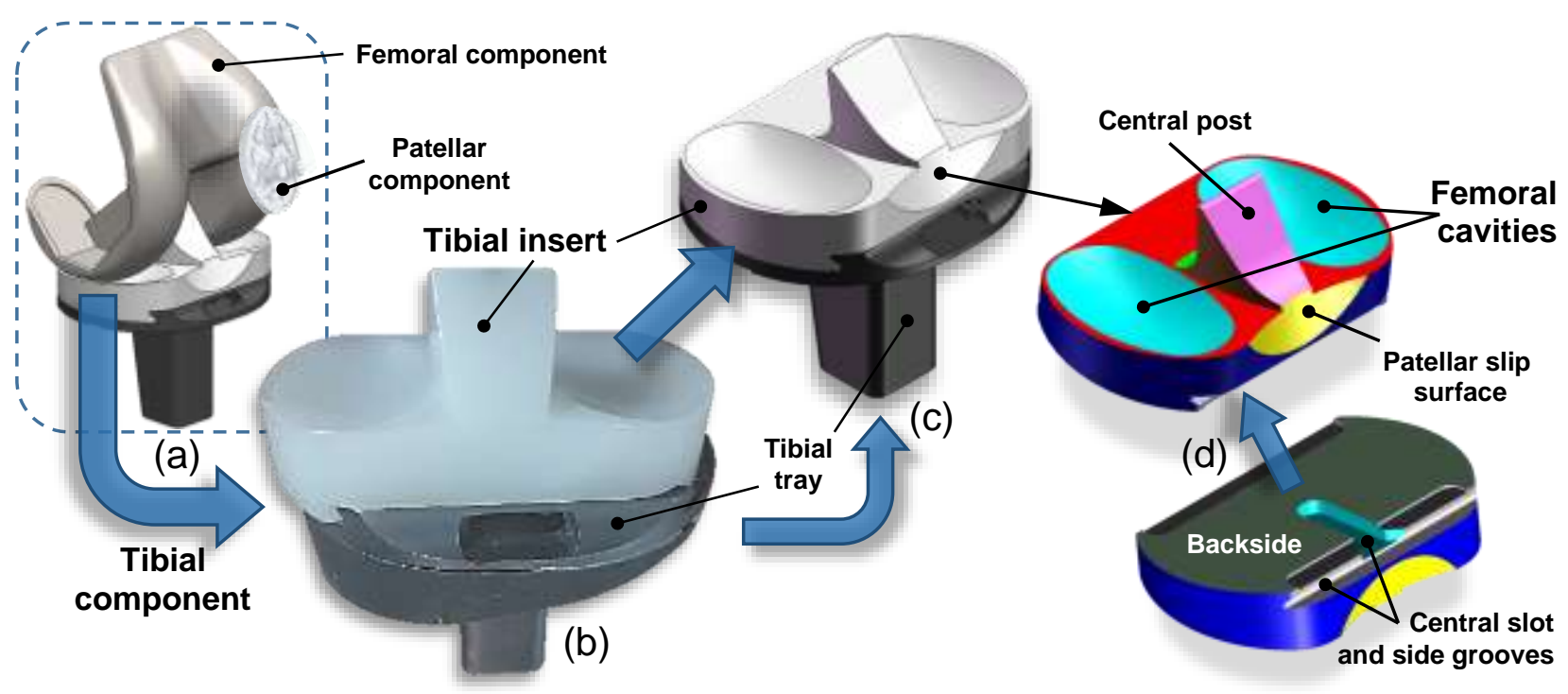

Fig. 1 a Knee prosthesis, tibial component of a: $\mathbf{b}$ real and $\mathbf{c}$ CAD model, and $\mathbf{d}$ tibial insert (top and backside views).

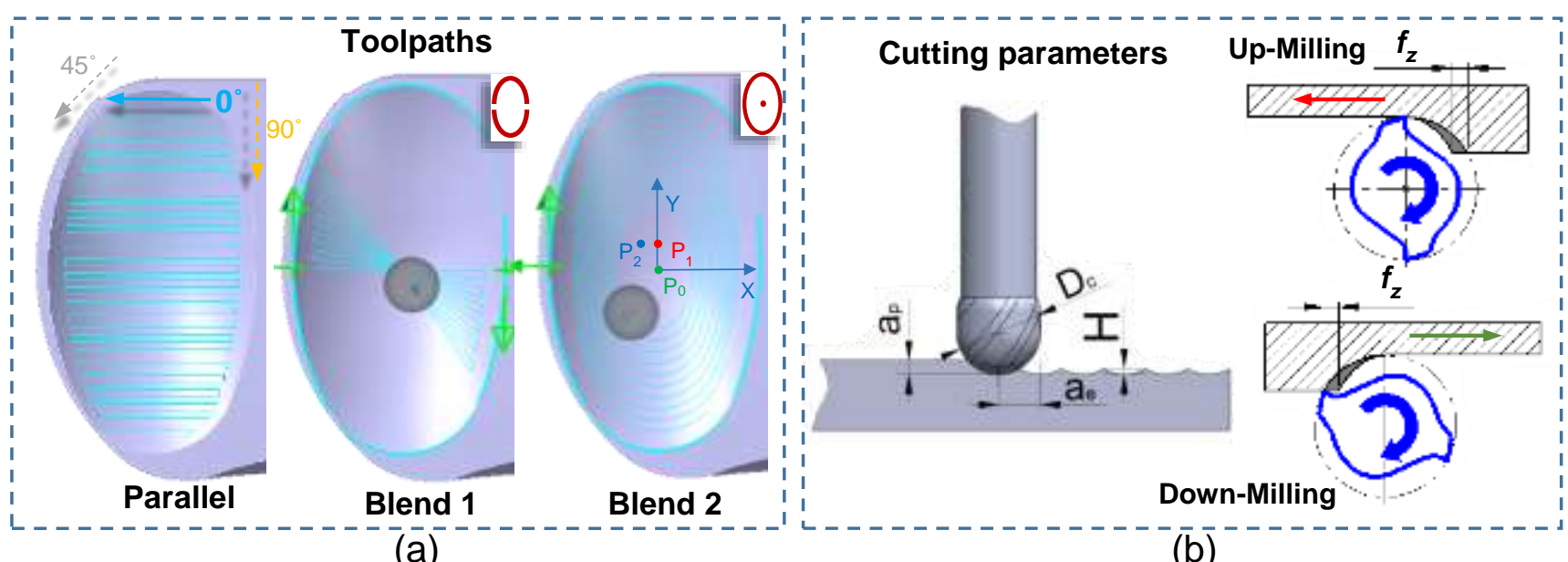

Fig. 2 Toolpaths used to finish the insert cavities: a Parallel and Blend with reference lines marked in red in the upper right corner, given as across and along, respectively and $\mathbf{b}$ definition of the cutting parameters. 


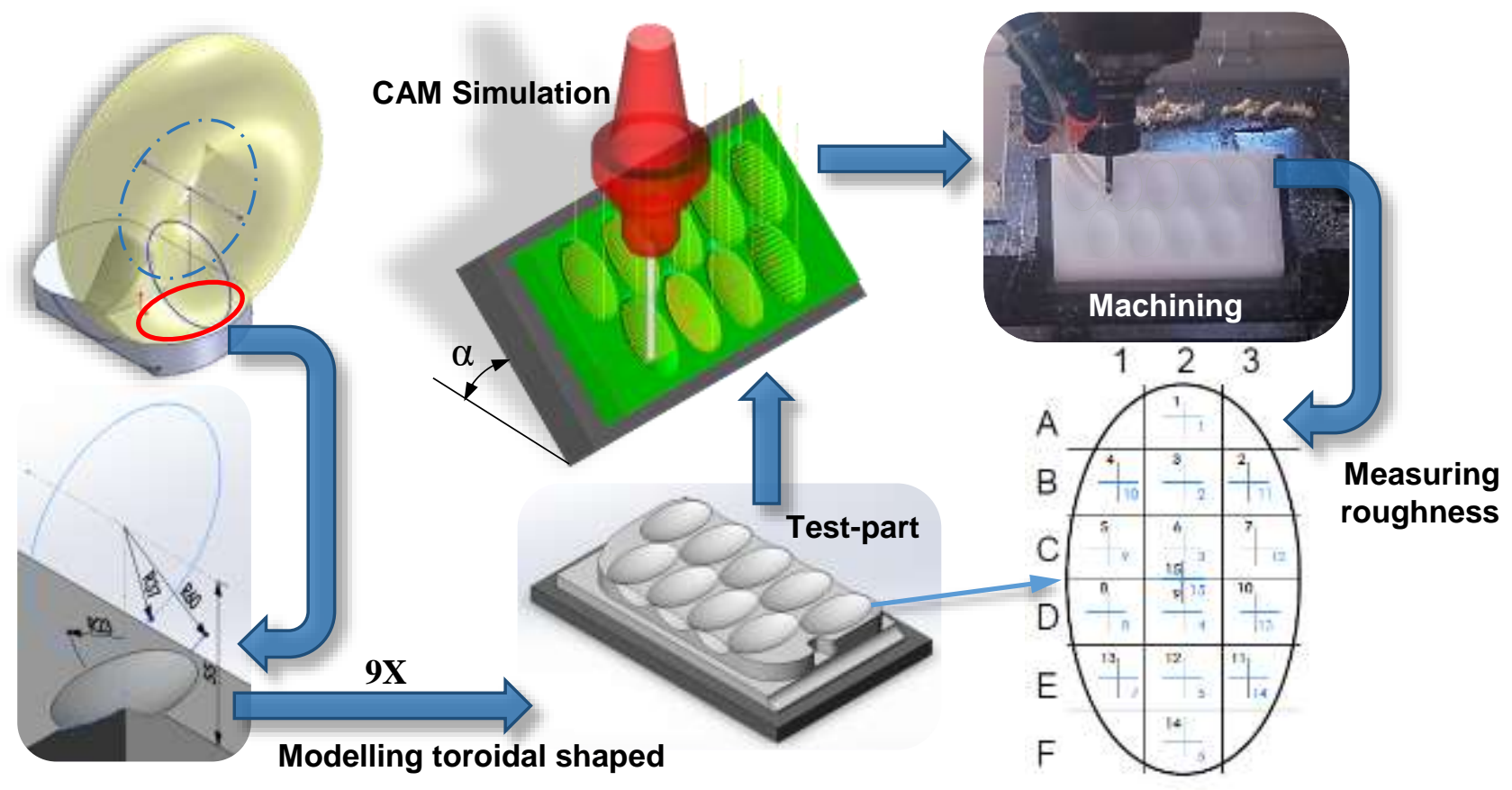

Fig. 3 CAD modelling, CAM simulation, machining and measuring the test-part used in the experiments.

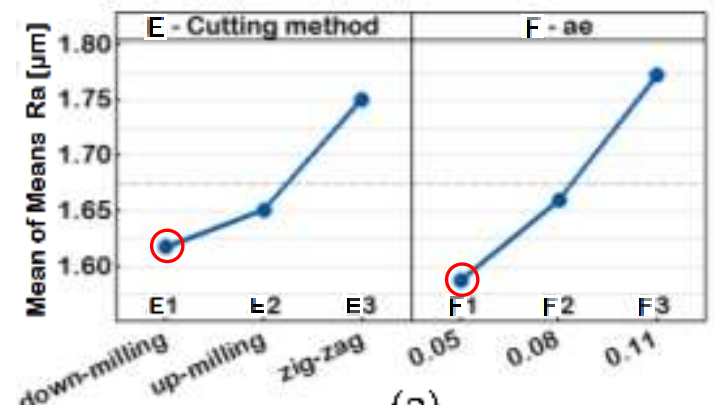

(a)

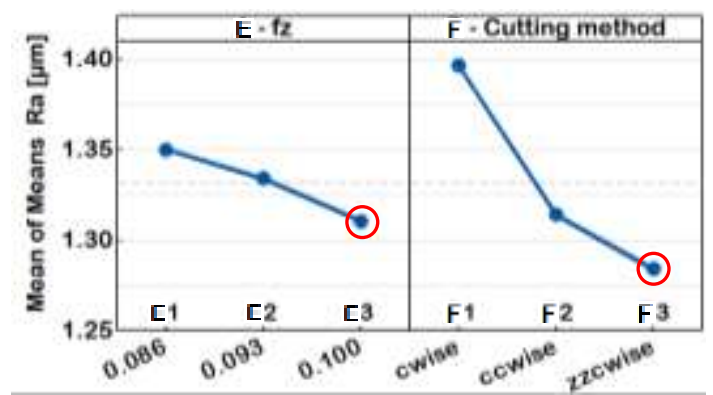

(b)

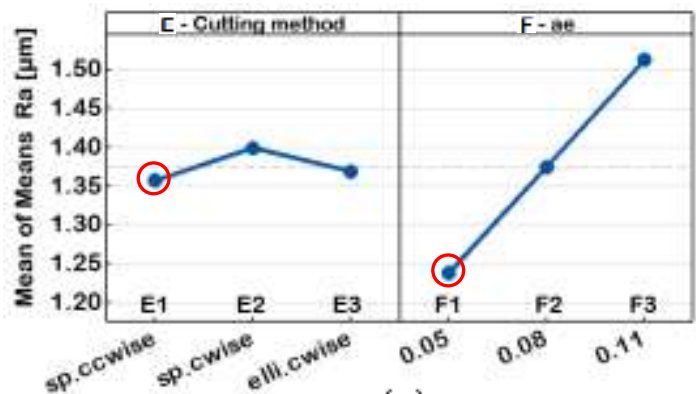

(c)

Fig. 4 Main effects plots for $R_{a}$ means to the toolpaths of stage 2: a Parallel, $\mathbf{b}$ Blend 1 and $\mathbf{c}$ Blend 2. 

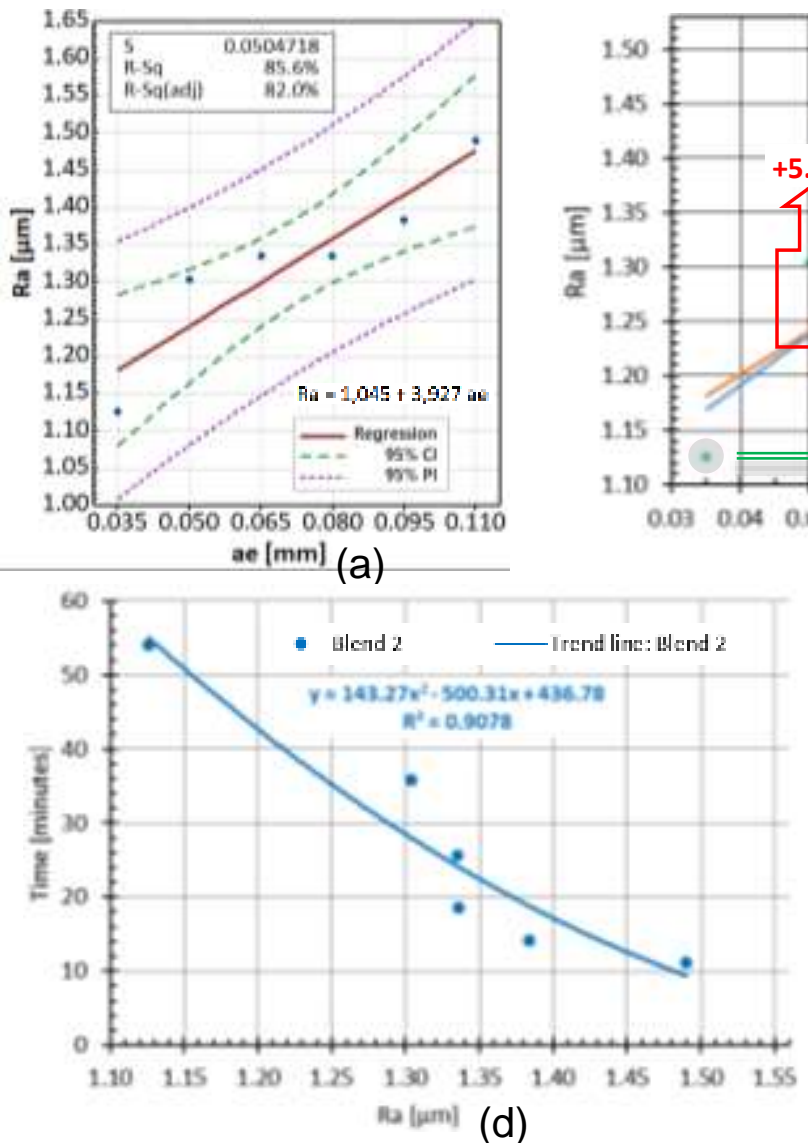

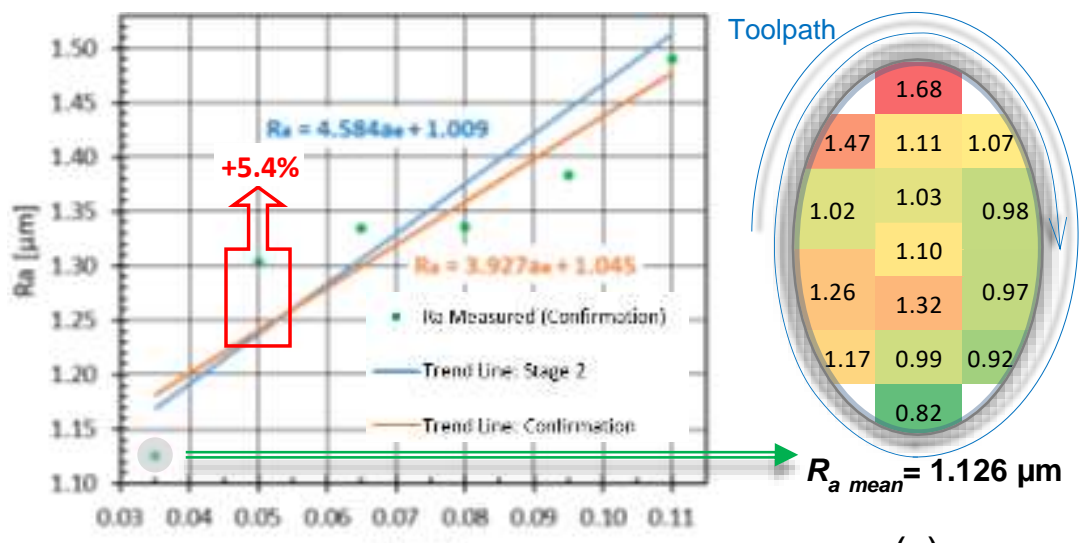

aelmm] (b)

(c)

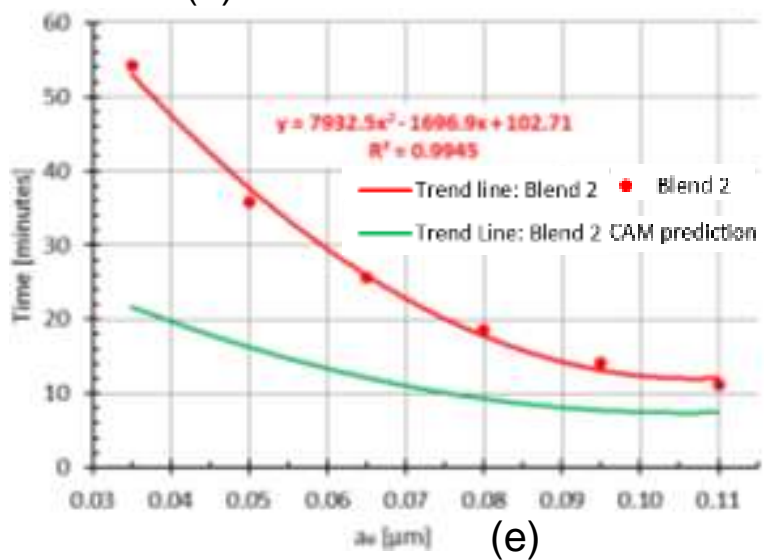

Fig. 5 Blend 2 confirmation test: a fitted line for the $R_{a}\left(a_{e}\right)$ parameter, with confidence and prediction intervals, b graphical comparison of the trend lines for stage 2 and for the confirmation, $\mathbf{c}$ mean values of $R_{a}[\mu \mathrm{m}]$, per zone $\left(a_{e}=\right.$ $0.035 \mathrm{~mm}$ ) and time of the cavity finishing operations, as a function of $\mathbf{d} R_{a}$ and $\mathbf{e} a_{e}$.

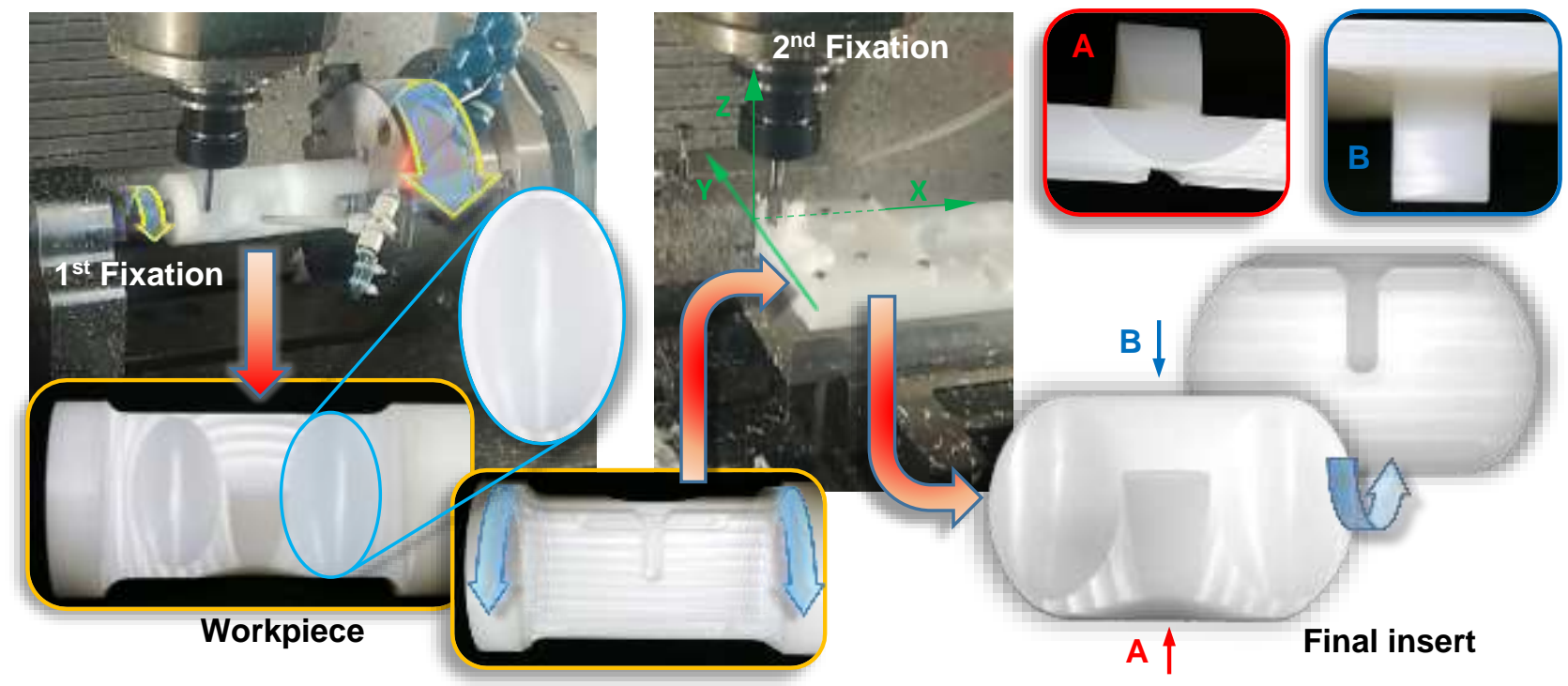

Fig. 6 Machining the prototype of the knee prosthesis insert. 
Table 1 Control factors and levels in the first stage of tests.

\begin{tabular}{|c|c|c|c|c|c|}
\hline \multirow{2}{*}{\multicolumn{2}{|c|}{ Toolpaths }} & \multicolumn{4}{|c|}{ Factors } \\
\hline & & A & B & $\mathbf{C}$ & D \\
\hline \multirow{4}{*}{ Parallel } & \multirow{4}{*}{ 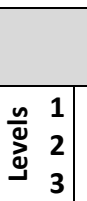 } & Cutting method & Orientation & $\begin{array}{c}\boldsymbol{a}_{\boldsymbol{e}} \\
{[\mathrm{mm}]}\end{array}$ & $\begin{array}{c}f_{z} \\
{[\mathrm{~mm} / \text { tooth] }}\end{array}$ \\
\hline & & Down-milling & $0^{\circ}$ & 0.12 & 0.090 \\
\hline & & Up-milling & $45^{\circ}$ & 0.10 & 0.093 \\
\hline & & Zig-zag & $90^{\circ}$ & 0.08 & 0.096 \\
\hline \multirow{4}{*}{ Blend 1} & \multicolumn{2}{|r|}{ Cutting method } & $\boldsymbol{a}_{e}[\mathrm{~mm}]$ & $\begin{array}{c}\boldsymbol{a}_{\boldsymbol{p}} \\
{[\mathrm{mm}]}\end{array}$ & $\begin{array}{c}f_{z} \\
{[\mathrm{~mm} / \text { tooth] }}\end{array}$ \\
\hline & $\simeq 1$ & Counter clockwise & 0.08 & 0.24 & 0.090 \\
\hline & 2 & Clockwise & 0.10 & 0.27 & 0.093 \\
\hline & $\stackrel{\Xi}{\unlhd} 3$ & Zig-zag clockwise & 0.12 & 0.30 & 0.096 \\
\hline \multirow{4}{*}{ Blend 2} & \multicolumn{2}{|r|}{ Cutting method } & Ref. point & $\begin{array}{c}a_{e} \\
{[\mathrm{~mm}]}\end{array}$ & $\begin{array}{c}f_{z} \\
{[\mathrm{~mm} / \text { tooth }]}\end{array}$ \\
\hline & \multirow{3}{*}{ 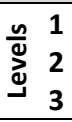 } & Spiral counter clockwise & Centred & 0.08 & 0.090 \\
\hline & & Spiral clockwise & Off centre 1 & 0.10 & 0.093 \\
\hline & & Elliptical clockwise & Off centre 2 & 0.12 & 0.096 \\
\hline
\end{tabular}

Table 2 Mean of $R_{a}$ - first stage results.

\begin{tabular}{|c|c|c|c|c|c|c|c|c|c|c|c|c|c|c|}
\hline & \multicolumn{4}{|c|}{ Factors } & \multirow[b]{2}{*}{$\begin{array}{c}\text { Sample } \\
\text { no. }\end{array}$} & \multicolumn{3}{|c|}{ Parallel $R a[\mu \mathrm{m}]$} & \multicolumn{3}{|c|}{ Blend $1 \mathrm{Ra}[\mu \mathrm{m}]$} & \multicolumn{3}{|c|}{ Blend $2 \mathrm{Ra}[\mu \mathrm{m}]$} \\
\hline & A & B & C & D & & Run 1 & Run 2 & Mean & Run 1 & Run 2 & Mean & Run 1 & Run 2 & Mean \\
\hline \multirow{9}{*}{ 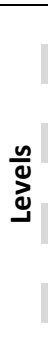 } & 1 & 1 & 1 & 1 & 1 & 1.728 & 1.631 & 1.680 & 1.359 & 1.312 & 1.336 & 1.327 & 1.291 & 1.309 \\
\hline & 1 & 2 & 2 & 2 & 2 & 1.658 & 1.651 & 1.654 & 1.256 & 1.229 & 1.242 & 1.409 & 1.430 & 1.419 \\
\hline & 1 & 3 & 3 & 3 & 3 & 1.765 & 1.639 & 1.702 & 1.273 & 1.306 & 1.290 & 1.694 & 1.703 & 1.698 \\
\hline & 2 & 1 & 2 & 3 & 4 & 1.718 & 1.585 & 1.652 & 1.341 & 1.335 & 1.338 & 1.948 & 1.968 & 1.958 \\
\hline & 2 & 2 & 3 & 1 & 5 & 1.651 & 1.519 & 1.585 & 1.383 & 1.396 & 1.390 & 1.907 & 1.856 & 1.881 \\
\hline & 2 & 3 & 1 & 2 & 6 & 1.787 & 1.692 & 1.734 & 1.266 & 1.258 & 1.262 & 1.645 & 1.613 & 1.629 \\
\hline & 3 & 1 & 3 & 2 & 7 & 1.678 & 1.518 & 1.598 & 1.190 & 1.199 & 1.194 & 1.532 & 1.515 & 1.523 \\
\hline & 3 & 2 & 1 & 3 & 8 & 2.116 & 1.927 & 2.021 & 1.285 & 1.349 & 1.317 & 1.493 & 1.505 & 1.499 \\
\hline & 3 & 3 & 2 & 1 & 9 & 1.860 & 1.623 & 1.742 & 1.352 & 1.343 & 1.347 & 1.676 & 1.599 & 1.638 \\
\hline
\end{tabular}

Table 3 Response tables, of the parameter $R_{a}$, for the means of the toolpaths tested in stage 1 .

\begin{tabular}{|c|c|c|c|c|}
\hline \multicolumn{5}{|c|}{ Parallel } \\
\hline Level & $A$ & B & C & D \\
\hline 1 & 1.679 & 1.643 & 1.814 & 1.669 \\
\hline 2 & 1.659 & 1.754 & 1.683 & 1.664 \\
\hline 3 & 1.787 & 1.728 & 1.628 & 1.792 \\
\hline Delta & 0.128 & 0.110 & 0.185 & 0.128 \\
\hline Rank & 2 & 4 & 1 & 3 \\
\hline \multicolumn{5}{|c|}{ Blend 1} \\
\hline Level & A & B & C & D \\
\hline 1 & 1.289 & 1.289 & 1.305 & 1.358 \\
\hline 2 & 1.330 & 1.316 & 1.309 & 1.233 \\
\hline 3 & 1.286 & 1.300 & 1.291 & 1.315 \\
\hline Delta & 0.044 & 0.027 & 0.018 & 0.125 \\
\hline Rank & 2 & 3 & 4 & 1 \\
\hline \multicolumn{5}{|c|}{ Blend 2} \\
\hline Level & A & B & C & D \\
\hline 1 & 1.476 & 1.597 & 1.479 & 1.609 \\
\hline 2 & 1.823 & 1.600 & 1.672 & 1.524 \\
\hline 3 & 1.553 & 1.655 & 1.701 & 1.719 \\
\hline Delta & 0.347 & 0.058 & 0.222 & 0.195 \\
\hline Rank & 1 & 4 & 2 & 3 \\
\hline
\end{tabular}


Table 4 Control factors and levels in the second stage of tests.

\begin{tabular}{|c|c|c|c|}
\hline \multirow{2}{*}{\multicolumn{2}{|c|}{ Toolpaths }} & \multicolumn{2}{|c|}{ Factors } \\
\hline & & \multirow{2}{*}{$\begin{array}{c}\text { E } \\
\text { Cutting method }\end{array}$} & \multirow{2}{*}{$\begin{array}{c}\mathbf{F} \\
\boldsymbol{a}_{e}[\mathrm{~mm}]\end{array}$} \\
\hline & & & \\
\hline Parallel & $\begin{array}{ll}\cong & 1 \\
\stackrel{\infty}{ \pm} & 2 \\
\unlhd & 3\end{array}$ & $\begin{array}{l}\text { Down-milling } \\
\text { Up-milling } \\
\text { Zig-zag }\end{array}$ & $\begin{array}{l}0.05 \\
0.08 \\
0.11\end{array}$ \\
\hline & & $f_{z}[\mathrm{~mm} /$ tooth $]$ & Cutting method \\
\hline Blend 1 & \begin{tabular}{ll}
$\cong$ & 1 \\
\hdashline & 2 \\
$\unlhd$ & 3
\end{tabular} & $\begin{array}{l}0.086 \\
0.093 \\
0.100 \\
\end{array}$ & $\begin{array}{c}\text { Clockwise } \\
\text { Counter clockwise } \\
\text { Zig-zag clockwise }\end{array}$ \\
\hline & & Cutting method & $a_{e}[\mathrm{~mm}]$ \\
\hline Blend 2 & 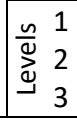 & $\begin{array}{c}\text { Spiral counter clockwise } \\
\text { Spiral clockwise } \\
\text { Elliptical clockwise }\end{array}$ & $\begin{array}{l}0.05 \\
0.08 \\
0.11 \\
\end{array}$ \\
\hline
\end{tabular}

Table 5 Mean of $R_{a}$ - second stage results.

\begin{tabular}{|c|c|c|c|c|c|c|c|c|c|c|c|}
\hline \multicolumn{2}{|c|}{ Factors } & \multirow[b]{2}{*}{$\begin{array}{c}\text { Sample } \\
\text { no. }\end{array}$} & \multicolumn{3}{|c|}{ Parallel $R a[\mu \mathrm{m}]$} & \multicolumn{3}{|c|}{ Blend $1 \mathrm{Ra}[\mu \mathrm{m}]$} & \multicolumn{3}{|c|}{ Blend $2 \mathrm{Ra}[\mu \mathrm{m}]$} \\
\hline E & $\mathbf{F}$ & & Run 1 & Run 2 & Mean & Run 1 & Run 2 & Mean & Run 1 & Run 2 & Mean \\
\hline 1 & 1 & 1 & 1.578 & 1.557 & 1.567 & 1.357 & 1.385 & 1.371 & 1.250 & 1.243 & 1.247 \\
\hline 2 & 1 & 2 & 1.527 & 1.538 & 1.533 & 1.390 & 1.434 & 1.412 & 1.278 & 1.257 & 1.267 \\
\hline 3 & 1 & 3 & 1.682 & 1.642 & 1.662 & 1.399 & 1.415 & 1.407 & 1.197 & 1.202 & 1.199 \\
\hline$\infty 1$ & 2 & 4 & 1.580 & 1.613 & 1.597 & 1.314 & 1.342 & 1.328 & 1.354 & 1.350 & 1.352 \\
\hline 22 & 2 & 5 & 1.665 & 1.590 & 1.628 & 1.345 & 1.321 & 1.333 & 1.374 & 1.388 & 1.381 \\
\hline-3 & 2 & 6 & 1.727 & 1.787 & 1.757 & 1.275 & 1.288 & 1.282 & 1.392 & 1.391 & 1.392 \\
\hline 1 & 3 & 7 & 1.671 & 1.708 & 1.690 & 1.358 & 1.345 & 1.352 & 1.474 & 1.472 & 1.473 \\
\hline 2 & 3 & 8 & 1.811 & 1.778 & 1.795 & 1.253 & 1.262 & 1.257 & 1.596 & 1.504 & 1.550 \\
\hline 3 & 3 & 9 & 1.811 & 1.858 & 1.834 & 1.244 & 1.243 & 1.243 & 1.527 & 1.505 & 1.516 \\
\hline
\end{tabular}

Table 6 Response tables of the $R_{a}$ parameter, for the means of the toolpath tested in stage 2 .

\begin{tabular}{|lrr|lrr|lrc|}
\hline & Parallel & & \multicolumn{3}{c|}{ Blend 1 } & \multicolumn{3}{c|}{ Blend 2 } \\
\hline Level & $\mathbf{E}$ & $\mathbf{F}$ & Level & $\mathbf{E}$ & $\mathbf{F}$ & Level & E & F \\
\hline 1 & 1.618 & 1.587 & 1 & 1.350 & 1.397 & 1 & 1.369 & 1.238 \\
2 & 1.652 & 1.660 & 2 & 1.334 & 1.314 & 2 & 1.357 & 1.375 \\
3 & 1.751 & 1.773 & 3 & 1.311 & 1.284 & 3 & 1.399 & 1.513 \\
\hline Delta & 0.133 & 0.186 & Delta & 0.039 & 0.113 & Delta & 0.042 & 0.275 \\
\hline Rank & $\mathbf{2}$ & $\mathbf{1}$ & Rank & $\mathbf{2}$ & $\mathbf{1}$ & Rank & $\mathbf{2}$ & $\mathbf{1}$ \\
\hline
\end{tabular}

Table 7 Importance of each factors and optimal level in the several toolpaths of stage 2.

\begin{tabular}{|c|c|c|c|c|c|}
\hline \multirow[b]{2}{*}{ Toolpath } & \multicolumn{4}{|c|}{ Dominant factors in the $R_{a}$ parameter and optimal levels } & \multirow[b]{2}{*}{ Regression $R_{a}[\mu \mathrm{m}]$} \\
\hline & 10 & $\begin{array}{c}\text { Contribution } \\
\text { P-value }\end{array}$ & 20 & $\begin{array}{c}\text { Contribution } \\
\text { P-value }\end{array}$ & \\
\hline \multirow{2}{*}{ Parallel } & $a_{e}[\mathrm{~mm}]$ & \multirow{2}{*}{$\begin{array}{c}59.3 \% \\
P=0.002\end{array}$} & Cutting method & \multirow{2}{*}{$\begin{array}{c}33.1 \% \\
P=0.015\end{array}$} & \multirow{2}{*}{$R_{a}=1.3703+3.094 a_{e}$} \\
\hline & 0.05 & & down-milling & & \\
\hline \multirow{2}{*}{ Blend 1} & Cutting method & \multirow{2}{*}{$\begin{array}{c}68.2 \% \\
P=0.035\end{array}$} & $f_{z}[\mathrm{~mm} /$ tooth $]$ & \multirow{2}{*}{$\begin{array}{c}7.8 \% \\
P=0.260\end{array}$} & \multirow{2}{*}{$R_{a}=1.284$} \\
\hline & Zig-zag clockwise & & 0.100 & & \\
\hline \multirow{2}{*}{ Blend 2} & $a_{e}[\mathrm{~mm}]$ & \multirow{2}{*}{$\begin{array}{c}94.8 \% \\
P=0.000\end{array}$} & Cutting method & \multirow{2}{*}{$\begin{array}{c}2.4 \% \\
P=0.220\end{array}$} & \multirow{2}{*}{$R_{a}=1.0085+4.584 a_{e}$} \\
\hline & 0.05 & & spiral ccwise & & \\
\hline
\end{tabular}


Table 8 Results of the Blend 2 confirmation tests for the $R_{a}$ parameter.

\begin{tabular}{|c|c|c|c|c|c|}
\hline \multirow{2}{*}{\multicolumn{2}{|c|}{$\begin{array}{c}\text { Sample } \\
\text { no. }\end{array}$}} & \multirow{2}{*}{$\begin{array}{c}\text { Factor } \\
a_{e}[\mathrm{~mm}]\end{array}$} & \multicolumn{3}{|c|}{$R_{a}[\mu \mathrm{m}]$} \\
\hline & & & Run 1 & Run 2 & Mean \\
\hline \multirow{6}{*}{$\frac{n}{a}$} & 1 & 0.035 & 1.135 & 1.117 & 1.126 \\
\hline & 2 & 0.050 & 1.303 & 1.304 & 1.304 \\
\hline & 3 & 0.065 & 1.338 & 1.332 & 1.335 \\
\hline & 4 & 0.080 & 1.331 & 1.341 & 1.336 \\
\hline & 5 & 0.095 & 1.371 & 1.396 & 1.384 \\
\hline & 6 & 0.110 & 1.481 & 1.499 & 1.490 \\
\hline
\end{tabular}

Table 9 Analysis of variance of the regression, $R_{a}$ versus $\mathrm{a}_{\mathrm{e}}$, for toolpath Blend 2 (confirmation).

\begin{tabular}{|c|c|c|c|c|c|c|c|}
\hline \multicolumn{8}{|c|}{ Blend 2} \\
\hline Source & DF & SS Seq & Contribution & Adj SS & Adj MS & F-Value & P-Value \\
\hline Regression & 1 & 0.06072 & $85.63 \%$ & 0.06072 & 0.060721 & 23.84 & 0.008 \\
\hline$a_{e}[\mathrm{~mm}]$ & 1 & 0.06072 & $85.63 \%$ & 0.06072 & 0.060721 & 23.84 & 0.008 \\
\hline Error & 4 & 0.01019 & $14.37 \%$ & 0.01019 & 0.002547 & & \\
\hline Total & 5 & 0.07091 & $100.00 \%$ & & & & \\
\hline \multicolumn{8}{|c|}{ Model Summary } \\
\hline $\mathrm{S}$ & $\mathrm{R}-\mathrm{sq}$ & R-sq(adj) & PRESS & \multicolumn{2}{|c|}{$\mathrm{R}$-sq(pred) } & & \\
\hline 0.0504718 & $85.63 \%$ & $82.04 \%$ & 0.0275335 & \multicolumn{2}{|c|}{$61.17 \%$} & & \\
\hline \multicolumn{8}{|c|}{ Regression Equation } \\
\hline
\end{tabular}

